\title{
Increased rate of spinal trabecular bone loss in patients with inflammatory bowel disease
}

\author{
R J MOTLEY, E O CRAWLEY, C EVANS, J RHODES, AND J E COMPSTON
}

From the Departments of Gastroenterology, Medical Physics, Radiology, and Pathology, University Hospital of Wales, Cardiff

SUMMARY The rate of spinal trabecular bone loss during one year was measured in 54 patients with inflammatory bowel disease. The mean change in spinal bone mineral content was $-5 \cdot 1 \mathrm{mg} / \mathrm{ml}$ $\mathrm{K}_{2} \mathrm{HPO}_{4}$, representing $3 \%$ of the initial bone mineral content. The rate of bone loss showed a significant negative correlation with body mass index $(r=-0 \cdot 276, p<0.05)$ but no other significant correlations were found with other clinical or biochemical indices, including the total amount of prednisolone taken during the course of the study. Eleven patients had bone loss greater than $15 \mathrm{mg} /$ $\mathrm{ml} /$ year; these included four non-steroid treated patients, two of whom had disease confined to the large bowel. The results indicate rapid rates of bone loss in some patients with inflammatory bowel disease over the course of one year. Although steroid therapy and malnutrition are likely to be contributory factors in some patients, other, as yet unidentified, risk factors also operate. The rapid bone loss observed in some patients emphasises the need for effective prophylactic regimes.

Osteoporosis has been reported in association with intestinal disease $\mathrm{I}^{-4}$ and we have recently shown an increased prevalence of spinal osteoporosis in a large unselected group of patients with inflammatory bowel disease, using quantitative computed tomography. In some patients, particularly young women with amenorrhoea and high dose steroid therapy, severe clinical manifestations of osteoporosis were seen with bone pain, spinal deformity and height loss resulting from vertebral crush fractures.

The development of quantitative computed tomography for the assessment of bone mineral content has enabled, for the first time, measurements at these clinically relevant sites of sufficient precision for rates of bone loss to be calculated; however, to date no longitudinal measurements of spinal bone density have been reported in intestinal disease. We have done repeat measurements of spinal trabecular bone mineral content in 54 patients with inflammatory bowel disease after a period of one year, in order to assess the rate of bone loss in such patients and to identify further the risk factors involved in the

Address for correspondence: Dr J E Compston. Department of Pathology. University of Wales College of Medicine. Heath Park, Cardiff CF4 4XN. Received for publication 15 April 1988. development of osteoporosis associated with intestinal disease.

Methods

PATIENTS

Seventy five consecutive patients, 46 women, with inflammatory bowel disease who were attending a gastroenterology clinic had initial measurements of spinal trabecular bone mineral content. Fifty four $(72 \%)$ of these aged $22-78$ years (mean 47 ), 33 women, attended after a period of $10-18$ months (mean 13.8) for repeat measurement. Of these 54 patients, 27 had small intestinal disease (Crohn's disease 26 , carcinoid one) and 21 had large intestinal disease (19 ulcerative colitis, two Crohn's colitis). Six patients had Crohn's disease affecting both small and large bowel. Of the 34 patients with Crohn's disease, all but three had undergone at least one small intestinal resection. The total lifetime dose of prednisolone at the start of the study ranged between 0 and $81 \mathrm{~g}$ (median $3.5 \mathrm{~g}$ ). During the year between the initial study and the repeat measurement, 29 of the 54 patients received prednisolone, the total dose during this period ranging from $0 \cdot 32-7 \cdot 3 \mathrm{~g}$ (median 
$2 \cdot 75 \mathrm{~g}$ ). Four patients were taking $1 \alpha$-hydroxyvitamin $\mathrm{D}_{3}$, three were taking calcium and vitamin $\mathrm{D}$ tablets BPC, one was taking calcium supplements, and two were taking hormone replacement therapy. The body mass index was calculated as weight/(height) ${ }^{2}$.

\section{BIOCHEMISTRY}

Non-fasting serum calcium, phosphate, alkaline phosphatase, and albumin were measured by standard Technicon Autoanalyser methods.

\section{MEASUREMENT OF BONE MINERAL CONTENT}

Mineral concentrations in the anterior part of the first, second, and third lumbar vertebral bodies were measured with a Philips $350 x$-ray computed tomography (CT) scanner, using a modification of the method of Cann and Genant.' Patients were positioned with the lumbar spine over a phantom containing tubes of various salt solutions and water. Scans were made through the middle of each vertebra, using a slice thickness of $6 \mathrm{~mm}$, field of view of $400 \mathrm{~mm}$ and tube voltage of $120 \mathrm{kV}$ and the mean CT number within the vertebral body of $\mathrm{L}_{1}, \mathrm{~L}_{2}$, and $\mathrm{L}_{3}$ was compared with those of the salt solutions. In this way, mineral concentrations were calculated in terms of the equivalent concentration of $\mathrm{K}_{2} \mathrm{HPO}_{4}$ solution, a salt which has similar radiographic attenuation properties to calcium hydroxyapatite. The results were corrected for the contribution of non-mineral components to the attenuation coefficient, using calculated values of estimated soft tissue corrections based on published tissue composition data. The

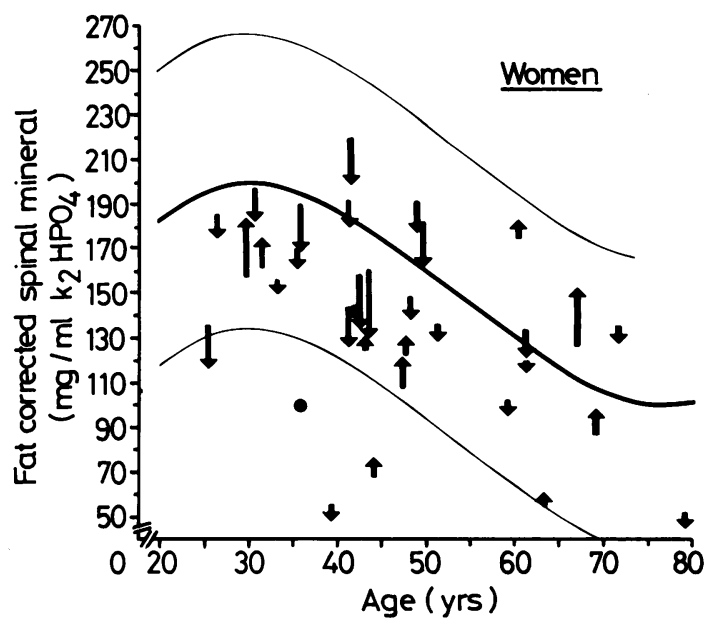

Fig. 1 Rates of spinal trabecular bone loss in female patients with inflammatory bowel disease. Results are expressed in terms of the equivalent concentration of $\mathrm{K}_{2} \mathrm{HPO}_{4}$. The arrows indicate the magnitude and direction of change. The normal values, taken from the data of Cann and Genant ' are shown as the mean value (heavy line) $\pm 2 S D$ (light lines).

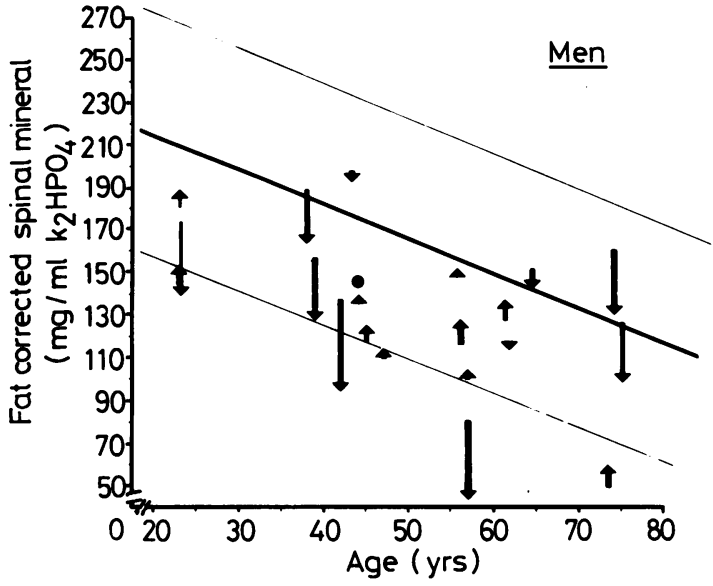

Fig. 2 Rates of spinal trabecular bone loss in male patients with inflammatory bowel disease. Results are expressed in terms of the equivalent concentration of $\mathrm{K}_{2} \mathrm{HPO}_{4}$. The arrows indicate the magnitude and direction of change. The normal values taken from the data of Cann and Genant' are shown as the mean value (heavy line) $\pm 2 S D$ (light lines).

non-mineral or soft tissue component consists of red marrow, yellow marrow, and the collagen matrix, the partial attenuation coefficients of each of these tissues being found from published values of density and percentage by weight of constituent elements, together with interpolated values of atomic cross

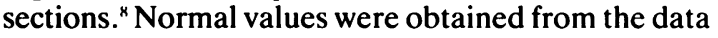
of Cann and Genant, ${ }^{7}$ to which the same correction procedure had been applied. The short term in vivo reproducibility of the measurement in our hands, assessed by repeat measurements in six subjects over a period of six hours or less, is $2.3 \%$. The long term in vitro precision, studied by carrying out repeat measurements on a phantom after a period of 12-18 months (total 14 measurements) was $1.2 \%$. The combined precision was calculated as $\sqrt{\left(2 \cdot 3^{2}+(1 \cdot 2)^{2}\right.}$ $=2 \cdot 6 \%$, corresponding to $3.1 \mathrm{mg} / \mathrm{ml} \mathrm{K}_{2} \mathrm{HPO}_{4}$.

\section{STATISTICAL ANALYSIS}

For normally distributed data, correlations were examined by linear regression analysis. Where data were non-normally distributed, a Mann-Whitney rank correlation was used. The significance of correlation coefficients was established using a twotailed $t$ test.

\section{Results}

The change in spinal bone mineral content, corrected in each patient to give the rate of bone loss or gain per annum, is shown for women in Figure 1 and for men in Figure 2. Twenty nine patients $(54 \%)$ showed a 
decrease, $16(30 \%)$ showed an increase, and $9(16 \%)$ did not change. The change in spinal bone mineral content, expressed in absolute terms, ranged from $+10 \cdot 8 \mathrm{mg} / \mathrm{ml} \mathrm{K}_{2} \mathrm{HPO}_{4}$ to $-37 \cdot 0 \mathrm{mg} / \mathrm{ml}($ mean $-5 \cdot 1)$. Expressed as a percentage of the initial bone mineral content, the change ranged from $+27 \cdot 0 \%$ to $-47 \cdot 0 \%$ (mean -3). No significant correlation was found between the rate of bone loss and serum calcium, phosphate, albumin, alkaline phosphatase, body weight, body height, duration of disease or total dose of prednisolone during the time over which the study was carried out. There was a significant negative correlation, however, between the body mass index and rate of bone loss $(r=-0 \cdot 276, p<0 \cdot 05)$.

As the combined precision of the method of measurement was $2 \cdot 6 \%$ or $3 \cdot 1 \mathrm{mg} / \mathrm{ml} \mathrm{K}_{2} \mathrm{HPO}_{4}$, differences greater than $9.3 \mathrm{mg} / \mathrm{ml} \mathrm{K}_{2} \mathrm{HPO}_{4}$ should be reliably detectable in an individual; to allow for some margin of additional error we chose a point of $15 \mathrm{mg} / \mathrm{ml}$ above which changes could definitely be regarded as significant. Eleven patients, seven men, aged 23-74 years (median 42) showed a decrease in bone mineral content $>15 \mathrm{mg} / \mathrm{ml} \mathrm{K}_{2} \mathrm{HPO}_{4} /$ year. The decrease ranged from $17-37 \mathrm{mg} / \mathrm{ml}$ (mean 25), representing a decrease of $7 \cdot 7-46.3 \%$ (mean 18 ) of the initial bone mineral content. Of these 11 patients, four had ulcerative colitis, six Crohn's disease and one carcinoid. Further details of these patients are shown in the Table. The total dose of prednisolone during the course of the study ranged from $0-7.9 \mathrm{~g}$ (median 2.95); seven of the 11 patients $(64 \%)$ had received prednisolone during the study. Of the four patients with rapid bone loss who had not received steroids, two had small bowel disease with resections and two had ulcerative colitis. All the four women in this group were premenopausal and menstruating regularly. Of the two patients receiving hormone replacement therapy, one showed an increase of $5 \mathrm{mg} / \mathrm{ml} \mathrm{K}_{2} \mathrm{HPO}_{4} / \mathrm{yr}$ and the other a decrease of $8 \mathrm{mg} / \mathrm{ml} \mathrm{K}_{2} \mathrm{HPO}_{4} / \mathrm{yr}$.

Two patients, both women, aged 30 and 67 years, showed an increase in bone mineral content $>15$ $\mathrm{mg} / \mathrm{ml} \mathrm{K}_{2} \mathrm{HPO}_{4}$ (30 and $20 \mathrm{mg} / \mathrm{ml}$ respectively) representing percentage increases of 19 and $15.9 \%$ of the initial bone mineral content. Neither of these patients was receiving oestrogen therapy and both had been treated with prednisolone during the course of the study (total dose 1.7 and $0.4 \mathrm{~g}$ respectively).

\section{Discussion}

Our results show rapid rates of bone loss over the course of one year in some patients with inflammatory bowel disease. As would be expected in this group of patients, in whom the mean age was 47 years, the mean change in spinal bone mineral content was negative $\left(-5 \cdot 1 \mathrm{mg} / \mathrm{ml} \mathrm{K}_{2} \mathrm{HPO}_{4} / \mathrm{yr}\right.$ or $3 \%$ of the original bone mineral content). Eleven patients $(20 \%)$ showed a decrease of $15 \mathrm{mg} / \mathrm{ml}$ or more whilst two female patients showed increases of $>15 \mathrm{mg} / \mathrm{ml}$. The cut off point of $15 \mathrm{mg} / \mathrm{ml} \mathrm{K}_{2} \mathrm{HPO}_{4}$ was chosen as one above which changes could definitely be regarded as significant, bearing in mind the combined precision of the method and allowing some margin for additional errors. Although it may be important to identify these patients for clinical reasons, they should not be regarded as a separate group and it would be statistically invalid to compare them with the remaining patients. In one of the patients with an increase $>15 \mathrm{mg} / \mathrm{ml}$ who was aged 30 years, this may have represented a normal increment in bone mineral content during the attainment of peak bone mass but in the other, who was aged 67 years, the increase is more difficult to explain and was

Table Clinical details of patients with a decrease in bone mineral content $>15 \mathrm{mg} / \mathrm{ml} /$ year

\begin{tabular}{|c|c|c|c|c|c|c|c|c|c|c|c|}
\hline $\begin{array}{l}\text { Patient } \\
\text { no }\end{array}$ & Sex & $\begin{array}{l}\text { Age } \\
\text { (yrs) }\end{array}$ & Disease & $\begin{array}{l}S B \\
\text { disease }\end{array}$ & $\begin{array}{l}L B \\
\text { disease }\end{array}$ & $\begin{array}{l}S B \\
\text { resection }\end{array}$ & $\begin{array}{l}\text { Serum } \\
\text { albumin } \\
(\mathrm{g} / \mathrm{l})\end{array}$ & $\begin{array}{l}\text { Body } \\
\text { weight } \\
(\mathrm{kg})\end{array}$ & $\begin{array}{l}\text { Total dose } \\
\text { prednisolone* } \\
\text { (g) }\end{array}$ & $\begin{array}{l}\text { Absolute } \\
\text { decrease } \\
B M C \\
(\mathrm{mg} / \mathrm{ml} / \mathrm{yr})\end{array}$ & $\begin{array}{l}\% \text { Decrease } \\
B M C \\
\% / y r\end{array}$ \\
\hline 1 & $\mathrm{M}$ & 59 & CD & + & - & $\times 2$ & 37 & $43 \cdot 5$ & 3.7 & 37 & $46 \cdot 3$ \\
\hline 2 & $F$ & 42 & $C D$ & + & - & $\times 1$ & 40 & $52 \cdot 8$ & $2 \cdot 4$ & 21 & $13 \cdot 2$ \\
\hline 3 & $\mathbf{M}$ & 23 & CD & - & + & 0 & 51 & $91 \cdot 8$ & $7 \cdot 9$ & 31 & $17 \cdot 8$ \\
\hline 4 & $\mathrm{M}$ & 39 & UC & - & + & 0 & 43 & $82 \cdot 8$ & $3 \cdot 2$ & 26 & $16 \cdot 7$ \\
\hline 5 & $\mathrm{~F}$ & 42 & CD & + & - & $\times 1$ & 35 & $47 \cdot 2$ & $7 \cdot 6$ & 24 & 14.9 \\
\hline 6 & $\mathrm{M}$ & 38 & UC & - & + & 0 & 36 & $53 \cdot 4$ & $6 \cdot 2$ & 22 & $11 \cdot 6$ \\
\hline 7 & $\mathrm{M}$ & 41 & $C D$ & + & - & $\times 2$ & 41 & $56 \cdot 6$ & $8 \cdot 0$ & 37 & $27 \cdot 0$ \\
\hline 8 & $\mathrm{~F}$ & 42 & $\mathrm{CD}$ & + & - & $\times 2$ & 41 & $55 \cdot 2$ & 0.00 & 17 & $7 \cdot 7$ \\
\hline 9 & $\mathrm{~F}$ & 49 & UC & - & + & 0 & 50 & $58 \cdot 3$ & $0 \cdot 00$ & 17 & $9 \cdot 3$ \\
\hline 10 & $\mathbf{M}$ & 74 & UC & - & + & 0 & 41 & $78 \cdot 2$ & 0.00 & 22 & $17 \cdot 5$ \\
\hline 11 & $\mathrm{M}$ & 73 & Carcinoid & + & - & $\times 3$ & 35 & $59 \cdot 8$ & $0 \cdot 00$ & 25 & $15 \cdot 5$ \\
\hline
\end{tabular}

$\mathrm{SB}=$ small bowel $\mathrm{LB}=$ large bowel: ${ }^{*}=$ represents total dose of prednisolone given over the course of the study 
not associated with any marked change in her clinical condition.

The rate of bone loss from the spine in normal subjects varies with age and sex, bone loss being most rapid in women during and immediately after the menopause. The approximate expected rate of bone loss in normal subjects can be inferred from the slopes shown in Figures 1 and 2, although these are derived from cross sectional data; both the data from Cann and Genant ${ }^{10}$ and others from another cross sectional study ${ }^{11}$ indicate a curvilinear decrease of $2.4 \%$ in spinal bone mineral content in women whilst in men, there is a linear decrease of $1 \cdot 2 .{ }^{12}$ The age of onset of bone loss is disputed, but may be as early as $30-35$ years in women. ${ }^{13}$ Rather lower rates of bone loss were reported in normal women by Riggs $e t a l$ in a longitudinal study; ${ }^{13}$ using dual photon absorptiometry to measure bone mineral content in the spine, these workers found a mean annual rate of bone loss of $1.2 \%$ and were unable to show any difference in the rate of bone loss between pre and postmenopausal women. In contrast, Genant et $\mathrm{al}^{14}$ reported a rate of bone loss of $6 \% /$ year in a longitudinal study of women who had undergone oophorectomy; these differences may be because of the different techniques used to measure bone mineral content, as quantitative computed tomography measures trabecular bone only, whereas dual photon absorptiometry includes cortical bone and any extraskeletal calcification in the field of measurement. Alternatively, the rate of bone loss after oophorectomy may be faster than after a natural menopause. It is also important to remember that bone loss may be phasic ${ }^{15}$ and thus results from longitudinal studies carried out over relatively short periods of time may be misleading. This reservation also applies to the present study and further studies are in progress to see if the rapid rates of bone loss observed in some patients are maintained.

The pathogenesis of osteoporosis associated with inflammatory bowel is incompletely understood, but corticosteroid therapy is likely to contribute in some patients. The deleterious effects of steroids on trabecular bone mass are well documented ${ }^{1617}$ and in our previous study of patients with inflammatory bowel disease those patients with osteoporosis had received a significantly higher lifetime dose of prednisolone than those with a normal bone mineral content. ${ }^{5}$ In the present study, we were unable to show any significant correlation between the rate of bone loss and prednisolone therapy during the course of the study, and $36 \%$ of patients with the most rapid bone loss had not received steroids over the preceding year whilst other patients who were receiving high doses of steroids did not show such rapid bone loss. These findings indicate that whilst steroid therapy may play a role in the pathogenesis of osteoporosis associated with inflammatory bowel disease, other factors are also important and can operate in the absence of steroid therapy; conversely, even relatively high doses of steroids are not inevitably accompanied by rapid bone loss.

Another factor which may contribute to osteoporosis in some women with inflammatory bowel disease is oestrogen deficiency and amenorrhoea appears to be a major risk factor in young women." All four women in the group with the most rapid bone loss were premenopausal and menstruating regularly and none had menopausal symptoms. In view of their age, however, some degree of oestrogen deficiency cannot be excluded and, if present, may have contributed to bone loss. ${ }^{1 \times}$

The relationship between the body mass index and rate of bone loss observed in this study suggests that the nutritional status and hence disease activity may be important determinants of bone loss in patients with inflammatory bowel disease. Disease activity could affect bone mass in several ways - for example, by increasing the likelihood of steroid therapy or by increasing calcium malabsorption in patients with active small bowel disease as a result of vitamin D deficiency, ${ }^{19}{ }^{211}$ rapid transit time, mucosal inflammation or intraluminal binding of calcium salts to fatty acids. $^{21}$ In addition, the nutritional status may directly affect bone mass, particularly if proteincalorie malnutrition is present. . $^{2}$

The increased prevalence of osteoporosis in association with inflammatory bowel disease and the presence of severe clinical effects of bone loss in some relatively young patients emphasise the importance of identifying those most at risk and establishing effective prophylaxis, particularly in view of the good prognosis of Crohn's disease in most patients. ${ }^{23}$ The pathogenesis of increased bone loss in these patients is likely to be multifactorial and whilst steroid therapy, oestrogen deficiency and malnutrition are all probable contributory factors, further studies are required to define risk factors more clearly. Until effective forms of prophylaxis have been established it seems advisable to advocate hormone replacement therapy for female patients with secondary amenorrhoea and for those entering the menopause; implant or percutaneous preparations may be preferable to oral forms because of variable intestinal absorption in some patients. In addition, steroid therapy should be constantly reviewed and kept to a minimum and a daily calcium intake of at least $1.5 \mathrm{~g}$ should be recommended.

We are grateful to Dr R Newcombe for his help with the statistical analysis. 


\section{References}

1 Salvesen HA, Boe J. Osteomalacia in sprue. Acta Med Scand 1953; 146: 290-9.

2 Nordin BEC. Effects of malabsorption syndrome on calcium metabolism. Proc $R$ Soc Med 1961; 54: 497-500.

3 Genant HK, Mall JC, Wagonfeld JB. Horst JV, Lanzl LH. Skeletal demineralization and growth retardation in inflammatory bowel disease. Invest Radiol 1976; 11: 541-9.

4 Hylander E, Ladefoged K, Madsen S. Calcium balance and bone mineral content following small intestinal resection. Scand J Gastroenterol 1981; 16: 167-76.

5 Compston JE, Judd D, Crawley EO, et al. Osteoporosis in patients with inflammatory bowel disease. Gut 1987; 28: $410-15$.

6 Genant HK, Cann CE, Boyd DP, Kolb FO, Ettinger B. Gordan GS. Quantitative computed tomography for vertebral mineral determination. In: Frame B. Potts JT, eds. Proceedings of Henry Ford symposium on clinical disorders of bone and mineral metabolism. Amsterdam: Excerpta Medica, 1983: 40-7.

7 Cann CE, Genant HK. Precise measurement of vertebral mineral content using computed tomography. J Comput Ass Tomogr 1980; 4: 493-500.

8 Crawley EO, Evans WD, Owen GM. The accuracy of single energy CT bone mineral measurements. Phys Med Biol (In press).

9 Christiansen C, Rodbro P. Long-term reproducibility of bone mineral content measurements. Scand J Clin Lab Invest 1977; 37: 321-3.

10 Cann CE, Genant HK, Kolb FO, Ettinger B. Quantitative computed tomography for prediction of vertebral fracture risk. Bone 1985; 6: 1-7.

11 Krolner B, Pors Nielson S. Bone mineral content of the lumbar spine in normal and osteoporotic women: cross-sectional and longitudinal studies. Clin Sci 1982; 62: $329-36$

12 Aloia JF, Vaswami A, Ellis K, Yuen K, Cohn SH. A model for involutional bone loss. J Lab Clin Med 1985; 106: $630-7$.
13 Riggs BL. Wahner HW, Melton LJ, Richelson LS, Judd HL, Offord KP. Rates of bone loss in the axial and appendicular skeletons of women: evidence of substantial vertebral bone loss prior to menopause. J Clin Invest 1986; 77: 1487-91.

14 Genant HK, Cann CE, Ettinger B, Gordan CG. Quantitative computed tomography of vertebral spongiosa: a sensitive method for detecting early bone loss after oophorectomy. Ann Intern Med 1982; 97; 699-705.

15 Ruegsegger P. Dambacher MA, Ruegsegger E, Fischer JA, Anliker M. Bone loss in premenopausal and postmenopausal women. J Bone Jt Surg 1984; 66A: 1015-23.

16 Curtiss PH. Clark WS, Herndon $\mathrm{CH}$. Vertebral fractures resulting from prolonged cortisone and corticotrophin therapy. JAMA 1954; 156: 467-9.

17 Hahn TJ, Boisscau K. Avioli LV. Effect of chronic corticosteroid administration on diaphyseal and metaphyseal bone mass. J Clin Endocrinol Metab 1974; 39: 274-82.

18 Lindsay R, Hart DM, Forrest C. Baird C. Prevention of spinal ostcoporosis in oophorectomised women. Lancet 1980; ii: 1151-3.

19 Compston J, Creamer B. Plasma levels and intestinal absorption of 25-hydroxyvitamin $\mathrm{D}$ in patients with small bowel resection. Gut 1977: 18: 171-5.

20 Harries AD, Brown R, Heatley RV, Williams LA, Woodhead JS. Rhodes J. Vitamin D status in Crohn's disease: association with nutrition and disease activity. Gut 1985; 26: 1197-203.

21 Southgate DAT, Widdowson EM. Smits BJ. Cooke WT. Walker CHM. Mathers NP. Absorption and excretion of calcium and fat by young infants. Lancet 1969; i: 487-9.

22 Adams P, Berridge FR. Effects of Kwashiorkor on cortical and trabecular bone. Arch Dis Childh 1969; 44: $705-9$.

23 Binder V, Hendriksen C, Kreiner S. Prognosis in Crohn's disease - based on results from a regional patient group from the county of Copenhagen. Gut 1985; 26: $158-63$. 